\title{
Acute gamma irradiated Stevia rebaudiana Bertoni enhanced particular types of steviol glycosides
}

\author{
Miao Si Chiew ${ }^{a}$, Kok Song Lai ${ }^{a}$, Sobri Hussein ${ }^{\mathrm{b}}$, Janna Ong Abdullah ${ }^{\mathrm{a}^{*}}$ \\ ${ }^{a}$ Department of Cell and Molecular Biology, Faculty of Biotechnology and Biomolecular Sciences, Universiti Putra Malaysia, 43400 Serdang, \\ Selangor, Malaysia \\ 'Agrotechnology and Biosciences Division, Malaysia Nuclear Agency, 43000 Bangi, Selangor, Malaysia
}

Received 17th November 2018 / Accepted 17th January 2019

\begin{abstract}
Stevia rebaudiana Bertoni from Asteraceae family is commercially valuable for its steviol glycosides (SGs) contents, which is 300 times sweeter than commercial sugar. The bottleneck in Malaysia is the lack of suitable stevia varieties that are able to thrive well under her climatic conditions and still produce high SGs. Mutation induction including gamma irradiation is effective in generating genetic variations and developing new plant varieties with desired traits. This study was aimed to determine the effects of acute gamma irradiation on phenotypic changes and enhancement of SGs contents of Stevia rebaudiana Bertoni variety AKH L1 (herein after will be designated as AKH L1). In vitro shoot tip explants of AKH L1 were subjected to a gamma doses regime of 10Gy to 50Gy, following which phenotypic changes of the irradiated explants and subsequent regenerated plantlets were observed. All irradiated explants exhibited different survival rates, with the lowest at $9.33 \pm 8.33 \%$ when subjected to $50 \mathrm{~Gy}$, while all the control (non-irradiated explants) survived. The $\mathrm{LD}_{50}$ was found to be at $23 \mathrm{~Gy}$. Subsequent irradiation of 900 shoot tip explants at $23 \mathrm{~Gy}$, produced 468 surviving shoot tips, which were all capable to develop and successfully sub-cultured until the fourth generation, $\mathrm{M}_{4}$. These $\mathrm{M}_{4}$ in vitro mutant plantlets exhibited significant increase in the numbers of leaf $(16.07 \pm 5.19)$ and average leaf size $(1.12 \pm 0.26 \mathrm{~cm} x$ $0.54 \pm 0.15 \mathrm{~cm})$. HPLC analysis performed in parallel further revealed the mutant plants contained higher concentrations of stevioside (387.04ppm), rebaudioside A $(670.18 \mathrm{ppm})$ and rebaudioside D (106.26ppm) compared to the non-irradiated plantlets, which exhibited $96.87,194.42$ and $28.25 \mathrm{ppm}$, respectively.
\end{abstract}

Keywords: stevioside, rebaudioside A, rebaudioside D, HPLC, $\mathrm{LD}_{50}$ irradiation

\section{INTRODUCTION}

Stevia rebaudiana Bertoni, a perennial sweet herb belongs to the family Asteraceae, is one of the 154 members of the genus Stevia. This plant is the most important source of non-caloric natural sweeteners, and is mainly known as "Sweet Weed', "Sweet Leaf", "Sweet Herbs" and "Honey Leaf". The property of the species that called attention to the plant is the intense sweet taste of the leaves and aqueous extracts (Uddin et al.,
2006). The extract of the stevia plant contains mixture of various sweet steviol glycosides, designated as SGs, such as stevioside, rebaudioside $\mathrm{A}, \mathrm{B}, \mathrm{C}, \mathrm{D}, \mathrm{E}$ and $\mathrm{F}$, dulcoside $\mathrm{A}$, steviolbioside, steviolmonoside, and rubusoside, which accumulate in the leaves and is 300 times sweeter than sugar (Ahmad et al., 2011; Reis et al., 2011; Mathur \& Shekhawat, 2012). The compounds that made up the majority

\footnotetext{
* Author for correspondence: Dr. Janna Ong Abdullah, Department of Cell and Molecular Biology, Faculty of Biotechnology and Biomolecular Sciences, Universiti Putra Malaysia, 43400 Serdang, Selangor, Malaysia. Email-janna@upm.edu.my
} 
proportions of SGs are stevioside and rebaudioside $A$, and they have been extensively used in the food and beverage industry. Stevioside traditionally makes up the majority of the sweetener which comprises $60-70 \%$ of the total glycosides content and has been evaluated as being 110-270 times sweeter than sugar (Dubois, 2000). It is believed to give a somewhat bitter aftertaste, or reported as a "licorice" taste or lingering effect (Carakostas et al., 2008). Rebaudioside A (30-40\% of total sweet content) is of particular interest as it is 180-400 times sweeter than sugar and has more pleasant sweet taste and no bitter aftertaste (Carakostas et al., 2008). Therefore, a higher ratio of rebaudioside $A$ to stevioside indicates a better sweetness quality, and is hence, preferred as reported by Yadav et al. (2011).

Jain (2010) proposed that mutation breeding was preferred over traditional breeding methods and genetically modified organisms (GMO) in the past few years. This is because multiple traits mutants can be isolated in mutation induction, but only single trait can be introduced into the crop in a transgenic way. Also, mutation induction can help to establish mutant lines range and determine trait specific genes in order to create molecular gene database, for molecular and functional genomics study and improve bioinformatics for future plant varieties development (Jain, 2010). Radiation treatment of plants had been reported as one of the most familiar methods for induction of plant mutations (Oladosu et al., 2016). The newly developed mutant varieties were useful in developing new plant varieties as well as for functional studies of genes (Hase et al., 2000; Tanaka et al., 2002; Shikazono et al., 2003).

In Malaysia, stevia is not recognized as a commercial crop due to lack of suitable variety when it was first introduced in the mid-1970s (Armizatul et al., 2009). Stevia is a short day plant with a critical day length of at least about 13 hours (Lester, 1999). This is in line with Armizatul et al. (2009) report that stevia plant exhibited reduced vegetative growth and lower steviosides content when the day length in Malaysia was less than the critical 13 hours. Several improvements in crop quality and bioactive metabolites production through induced mutagenesis have been reported such as rice with low amylase and protein contents for diabetes people (Chen et al., 2006), maize with better protein contents (Tomlekova, 2010), and cassava with increased amylase content (Ceballos et al., 2008). Khalil et al. (2014) reported higher stevioside contents were obtained from in vitro shoots from irradiated seeds of stevia. With these promising results, induced mutagenesis has potential to be applied on stevia to develop new mutant varieties that are suitable for growing under Malaysia's climatic condition and increases its potential as a viable crop plant. SGs content is the key selling point for stevia, and hence, increasing or improving the yield of SGs is crucial. There is still limited report regarding research on the effect of gamma irradiation on the accumulation of SGs contents of stevia in Malaysia. Hence, the main objective of this study was to create new varieties of stevia with high particular types of sweet glycosides via acute gamma irradiation suitable for growing in Malaysia.

\section{MATERIALS AND METHODS}

Plant materials preparation. One-month-old potted Stevia rebaudiana Bertoni AKH L1 propagated from stem cutting were bought from nursery located at Denai Alam, Selangor (3.153028, 101.520538). The sterilization methods employed for in vitro plants initiation using potted stevia plants were slightly modified from Nurhidayah et al. (2014). Young, actively growing shoots were collected from one-month-old potted AKH L1 plants. Nodes measuring $2 \mathrm{~cm}$ were chosen as explants where each was cut and placed under running tap water for 20 minutes to remove traces of soil and dirt. Prior to treatments, the explants were shaken with $2 \mathrm{mg} / \mathrm{L}$ fungicide (Ridomil) for 5 minutes and rinsed thrice with distilled water. Under aseptic condition, the explants were surfaced sterilized with $70 \%(\mathrm{v} / \mathrm{v})$ ethanol for 30 seconds, followed by $5 \%(\mathrm{v} / \mathrm{v})$ commercial sodium hypochlorite for 15 minutes. Then, the explants were rinsed with sterile distilled water for four times and dried with sterile blotting paper.

Shoot induction and multiplication. Shoots induction was initiated using surface sterilized nodal explants cultured on full strength 
Murashige and Skoog (MS) basal medium (Murashige \& Skoog, 1962) containing $30 \mathrm{~g} / \mathrm{L}$ sucrose and solidified with $7.5 \mathrm{~g} / \mathrm{L}$ of agar (Gelrite) supplemented with $1 \mathrm{mg} / \mathrm{L}$ 6benzylaminopurine (BAP). The $\mathrm{pH}$ of the medium was adjusted to 5.8 before autoclaving at $121^{\circ} \mathrm{C}$ for 15 minutes. The cultures were incubated at $24 \pm 2^{\circ} \mathrm{C}$ with a 16 hours photoperiod and allowed for regeneration and multiplication for two weeks. Two types of explants (shoot tip and nodal segment) were used to determine which explants was more suitable for micropropagation. All cultures were examined after one month of incubation for the following parameters: shooting percentage, initiation time (day), number of shoot, shoot length and number of leaf. The regenerated shoots were cut, and shoot tips with four leaflets were placed on MS medium supplemented with 1 mg/L BAP. All experiments were repeated twice.

Acute gamma irradiation. One-week-old AKH L1 shoot tips with four leaflets were irradiated with gamma rays at different doses of $0,10,20$, 30, 40, and 50Gy using the Malaysia Nuclear Agency (MNA) Gamma Cell Facility, Bangi, Selangor, Malaysia at different doses of the source of gamma rays was Caesium ${ }^{137}$. Each experiment constituted 5 replicates per dose, with 5 explants per replicate. The whole experiment was repeated twice. The irradiated explants were cultured on basal MS medium and incubated at $24 \pm 2^{\circ} \mathrm{C}$ with a 16 hours photoperiod. After 4 weeks of culture, data were taken based on percentage of survival, length of explants, number of new shoots formed and number of leaves. The lethal dose, $\mathrm{LD}_{50}$ was calculated based on the percentage of survival, whereby further acute irradiation was carried out at the selected $\mathrm{LD}_{50}$ dose. The newly regenerated shoots were subcultured up to $\mathrm{M}_{4}$ generation for selection of steviol glycosides content.

Plant leaf extract preparation. The steviol glycosides content were analyzed for both $\mathrm{M}_{4}$ generation of irradiated and non-irradiated plantlets. The plant extracts preparation methods used were slightly modified from Abou-Arab et al. (2010). The leaves were randomly picked and dried under room temperature ranging from $25 \pm 2^{\circ} \mathrm{C}$ on the bench-top in the laboratory for three days. All the dried irradiated and nonirradiated stevia leaves were, separately, grounded into powder form by using mortar pestle. Approximately $0.4 \mathrm{~g}$ of powdered leaves was extracted in $10 \mathrm{ml}$ of distilled $\mathrm{H}_{2} \mathrm{O}$ in tubes placed in a beaker of water and allowed to boil for 15 minutes. The crude extracts containing steviol glycosides were cooled to room temperature for 5 minutes, and then filtered through Whatman filter paper No. 1. The filtrates were freeze-dried using the VirTis ${ }^{\circledR}$ BenchTop ${ }^{\text {TM }}$ " $K$ " Series Freeze Dryers (SP Industries, USA) for two days and stored at $4^{\circ} \mathrm{C}$ in airtight bottles.

Steviol glycosides analysis. Dried leaf extracts were subjected to High Performance Liquid Chromatography (HPLC) analysis. The HPLC system used was an Agilent 1260 Infinity (Agilent Technologies, CA, USA) equipped with an auto sampler, quaternary pump and a diode array detector. The HPLC method was performed using an Agilent Poroshell 120 C18 column $(3.0 \times 50 \mathrm{~mm}$, particle size $2.7 \mu \mathrm{m})$ and a UV detector set at $210 \mathrm{~nm}$. Separation was done with a ratio of ultrafiltration $80 / 20 \mathrm{H}_{2} \mathrm{O}$ :acetonitrile, set to a flow rate of $0.8 \mathrm{~mL} / \mathrm{min}$. The standards consisted of stevioside, rebaudioside $\mathrm{A}$ and rebaudioside D were run on the HPLC system and the retention time for each was recorded. Identification of stevioside, rebaudioside $\mathrm{A}$ and rebaudioside $\mathrm{D}$ in the plant leaf extracts were calculated by comparing the retention time of the samples with the standards. The results obtained for each sample were expressed in parts per million (ppm).

Data analysis. Each experiment was repeated twice and the data represented the means of three experiments. Statistical analyses of mean values, standard deviation $( \pm)$ and significant difference were carried out by using IBM-SPSS software Window version 20 . The data were subjected to One-Sample T Test or One Way Analysis of Variance (ANOVA) analysis and the means were compared by using Duncan's Multiple Range Test (DMRT) at significance $\mathrm{p}<0.05$.

\section{RESULTS AND DISCUSSION}


Establishment of in vitro stevia plantlets. Stevia rebaudiana Bertoni variety AKH L1 can be propagated by stem cutting, seed propagation and micropropagation (tissue culture method). It had been reported that seed propagation was not effective due to low fertility (Tadhani et al., 2006) and self-incompatibility of its flowers, while propagation through stem cutting has limitation on account of the low number of new plants (Miyagawa et al., 1986). Thus, by considering future needs of plant materials, micropropagation was chosen for rapid multiplication of stevia in this experiment. In vitro stevia plantlets were established from nodal explants excised from young, actively growing shoot tips of glasshouse grown, one-month-old potted AKH L1. The explants were sodium hypochlorite-ethanol sterilized prior culturing on MS medium supplemented with $1 \mathrm{mg} / \mathrm{L}$ BAP. Past findings by Thiyagarajan and Venkatachalam (2012) found that MS medium supplemented with $1 \mathrm{mg} / \mathrm{LBAP}$ was suitable for shoots multiplication of stevia. Thus this concentration of BAP was used in this study to mass propagate the AKH L1 plantlets. Shoots regenerated from nodal explants were observed after 7 days of culture, and newly regenerated plantlets were formed after one month. Shoot tips were cut and sub-cultured on fresh medium monthly to allow for regeneration (Figure 1).
Shoot tips were chosen as explants for mass propagation of stevia because it showed significantly $(\mathrm{p}<0.05)$ higher shooting percentage $(97.78 \%)$ and shorter initiation time (3.33 days) compared to nodal explants. Figure 2 clearly showed that shoot tip explants were better than nodal explants with respect to the number of shoots formed, shoot length increment and number of leaves produced. The tallest shoots $(10.50 \pm 2 \mathrm{~cm})$ were induced from shoot tip explants which produced significantly greater numbers of leaf $(20.67 \pm 3.06)$ as summarized in Table 1. These observations were similar to ElMotaleb et al. (2013) data whereby shoot tip explants also proved to perform better than nodal explants in terms of shooting percentage, shoot length achievement and shoot initiation time. Both Patil et al. (1996) and Mubarak et al. (2008) also reported that shoot tip explants gave the highest number of plantlets than nodal explants in micropropagation of stevia. This could probably be due to lower endogenous phytohormonal level in the nodes compared to the shoot tips. Introduction of BAP in the medium was found to elevate phytohormone concentration which enhanced shoots proliferation, and cutting off the shoot tips promoted lateral buds formation and rapid regeneration (El-Motaleb et al., 2013).

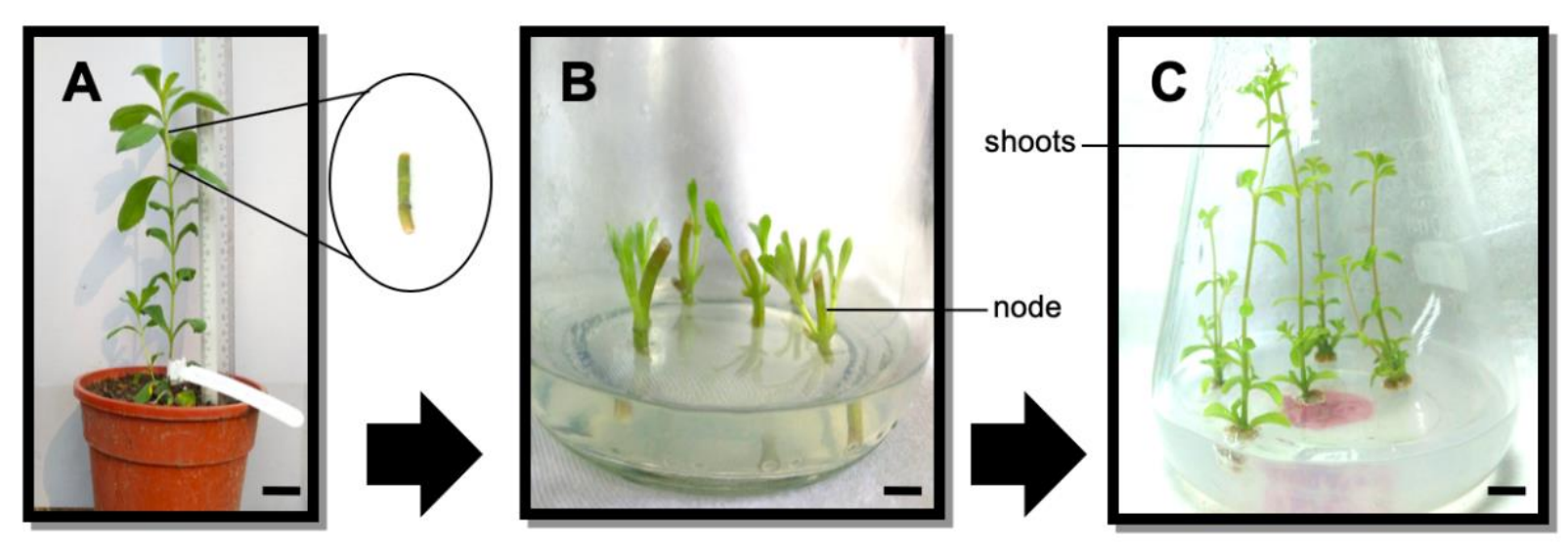

Figure 1. Initiation of in vitro culture of stevia variety AKH L1. (A) Approximately $2 \mathrm{~cm}$ long nodal explants obtained from young, actively growing shoot tips of one-month-old stevia potted plant. (Bar=3cm). (B) Shoots multiplication was initiated on MS supplemented with 1mg/L BAP for one month. $(\mathrm{Bar}=1 \mathrm{~cm})$. (C) Newly regenerated plantlets were sub-cultured to new medium monthly. $(\mathrm{Bar}=1 \mathrm{~cm})$. 


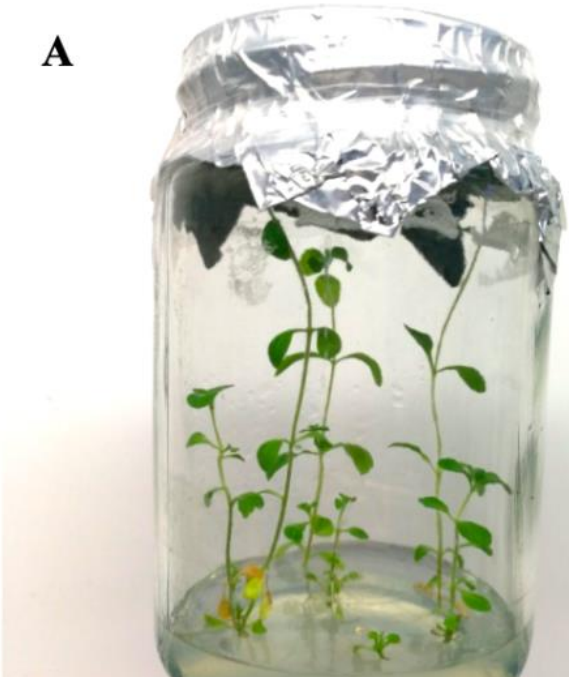

B

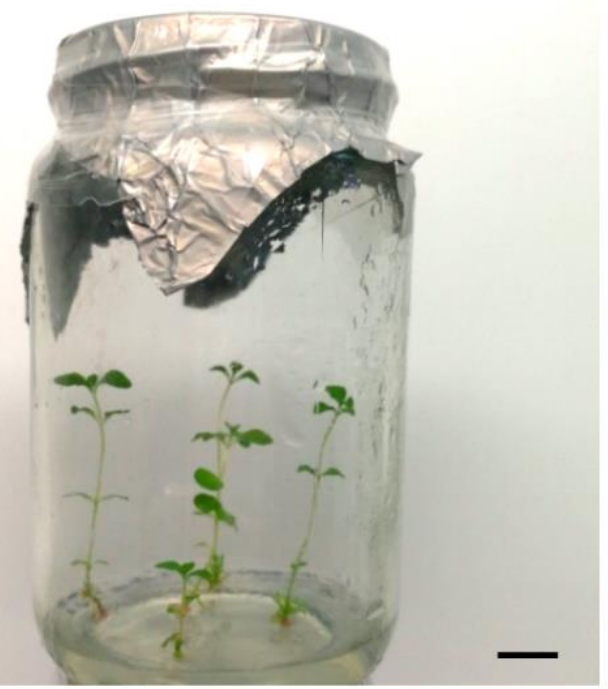

Figure 2. In vitro shoots initiation for plantlets production using different explant types on MS medium supplemented with $1 \mathrm{mg} / \mathrm{L}$ BAP after one month. (A) shoot tip; (B) node (Bar $=1 \mathrm{~cm})$.

Table 1. Growth profiles of different explant types of stevia variety AKH L1 after one month.

\begin{tabular}{cccccc}
\hline Explant types & $\begin{array}{c}\text { Shooting } \\
\text { percentage }\end{array}$ & $\begin{array}{c}\text { Initiation } \\
\text { time (day) }\end{array}$ & No. of shoots & $\begin{array}{c}\text { Shoot length } \\
(\mathbf{c m} \pm \text { SD) }\end{array}$ & No. of leaves \\
\hline Shoot tip & $97.78 \pm 3.85^{\mathrm{a}}$ & $3.33 \pm 0.58^{\mathrm{a}}$ & $6.33 \pm 1.53^{\mathrm{a}}$ & $10.50 \pm 2.00^{\mathrm{a}}$ & $20.67 \pm 3.06^{\mathrm{a}}$ \\
Node & $71.11 \pm 7.69^{\mathrm{b}}$ & $7.33 \pm 0.58^{\mathrm{b}}$ & $2.33 \pm 0.58^{\mathrm{b}}$ & $7.17 \pm 1.26^{\mathrm{b}}$ & $14.33 \pm 2.52^{\mathrm{b}}$
\end{tabular}

Data was taken from five replicates (with five explants per replicate) and the experiment was repeated twice. Superscripts within the means of each column (a-b) indicate significant difference among means $(p<0.05$, using One-Sample T Test). SD $=$ standard deviation.

Optimization of subculture cycle is crucial in order to obtain higher plantlets biomass with regenerative potency. However, information on the effects of repeated sub-culturing cycles on the rate of shoots multiplication and regeneration of in vitro stevia plantlets is scanty. In this study, it was observed that repeated subculturing cycles resulted in stunted growth of the regenerated plantlets (Figure 3). Gradual yellowing in some leaves were observed after repeated subculturing for 12 cycles. This indicated that the shoot cultures reduced their regeneration capacity (Ramanand, 2006). Somaclonal variations have been long known to be induced during dedifferentiation and regeneration of plants in tissue cultures (Filipecki \& Malepszy, 2006). Rapid multiplication and prolonged culturing may affect genetic stability and thus increased the frequency of somaclonal variation in in vitro culture (Petolino et al., 2003). The result paralleled Nakasha et al. (2016) findings whereby reduction in regenerative capacity was observed in Chlorophytum borivilianum after repeated subculture cycles of their callus cultures. Thus, frequent subculturing does seem to affect the stevia plantlets growth, hence is not recommended as it may compromise the quality of the in vitro cultures.

Acute irradiation of in vitro stevia plantlets. In any mutational induction studies, it is critical to determine that the dose of mutagen applied is able to induce desirable alterations with minimal unintended effects. The effective dose of mutagen used will ensure the success of mutational induction for desirable outcomes. Therefore, in order to obtain the effective dose of mutagen used, fixation of $\mathrm{LD}_{50}$ doses was deemed crucial before massive irradiation of similar materials was performed (Rajarajan et al., 2016). Lethal dose, $\mathrm{LD}_{50}$, was referred to a dosage at which greatest frequency of mutation occurred with half of the planting materials survived, while half died 
(Kangarasu et al., 2014). This $\mathrm{LD}_{50}$ value varies according to plants, genera and cultivars (Tah, 2006). In this study, the $\mathrm{LD}_{50}$ of in vitro shoot tips of stevia plantlets was determined to be $23 \mathrm{~Gy}$ (Figure 4). There were significant differences $(p<0.05)$ in the survival rates amongst the stevia shoots subjected to lower and higher doses of acute gamma irradiation. The survival rate was inversely proportional to the gamma irradiation dose. All the non-irradiated explants (control) survived while explants treated with 50Gy exhibited the lowest survival rate $(9.33 \pm 8.33 \%)$.

$\mathbf{A}$

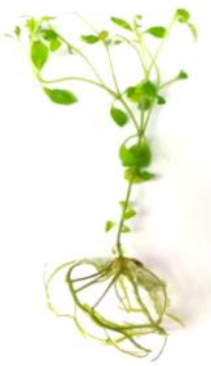

B

Figure 3. In vitro culture of stevia variety $\mathrm{AKH}$ L1. (A) $1^{\text {st }}$ generation plantlet; (B) $12^{\text {th }}$ generation clump of plantlets. (Bar $=1 \mathrm{~cm})$.

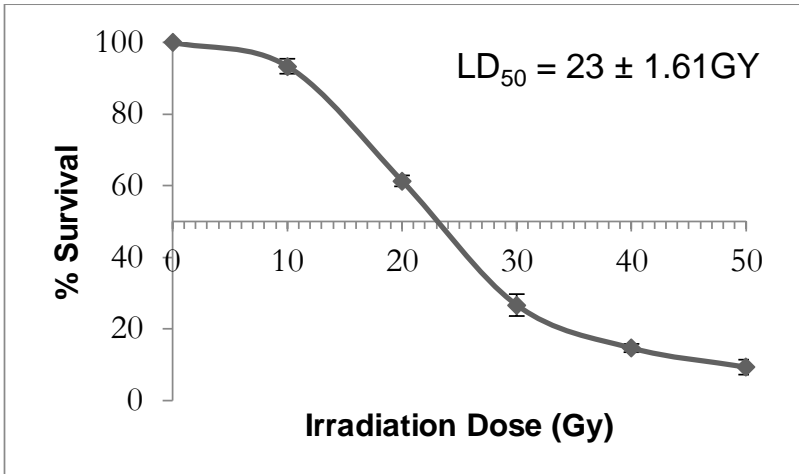

Figure 4. $\mathrm{LD}_{50}$ of stevia variety $\mathrm{AKH} \mathrm{L1}$ shoot tips after one month of culture. Data was taken from five replicates and the experiment was repeated twice. The data was the average of three experiments.

Table 2 depicts the mutagenic effects of different doses of gamma rays on in vitro growth of $\mathrm{AKH}$ L1 shoots and their survival rates. The data highlights that the gamma rays imposed significant effect on the regenerated shoots' length. The control exhibited the highest length $(2.53 \pm 0.36 \mathrm{~cm})$ while not much difference in shoot length was seen for explants exposed to 10 Gy $(2.44 \pm 0.67 \mathrm{~cm})$. Nevertheless, gamma doses greater than 30Gy did significantly reduce the length of the regenerated shoots compared to the control. It was more pronounced at 40Gy and 50 Gy which could be due to higher sensitiveness of stevia to higher doses (Figure 5). This observation paralleled Jamie's (2002) data which showed that the mutation rate increased when the amount of exposure to irradiation and intensities of gamma rays used were increased. Inhibition of seeds germination, seedlings growth and other biological responses were frequent occurrences observed in plants subjected to high gamma doses (Wi et al., 2007). Preussa and Britta (2003) attributed such inhibitive effects to be caused by cell cycle arrest at G2/M phase during somatic cell division and/or various damages in the entire genome.

Likewise, in this study, the highest number of regenerated shoots with mean value of 1.84 was observed in the control and no new shoots were formed at 40 and 50Gy. Unfortunately, the number of leaves was negatively affected by the gamma doses. The non-irradiated regenerated shoots (control) showed greater number of leaves at 16.52 \pm 5.05 . At 50Gy, necrosis of explants and poor development of regenerated leaves $(2.81 \pm 2.47)$ were observed. Increasing gamma irradiation dosage resulted in reduced survival rate, length of regenerated shoots, number of new shoots formed and the number of leaves formed. The radiosensitivity test for AKH L1 was successfully performed with a $\mathrm{LD}_{50}$ value of 23Gy.

Table 3 summarized the explants establishment percentage and the growth of control and irradiated stevia plantlets after four generations. It is recommended and a common practice for irradiated plantlets to be subjected to at least four generations/cycles of sub-culturings in order to screen off potential chimeras and to select for stable mutants. Therefore, $\mathrm{M}_{4}$ generation was chosen to maximize the probability of obtaining stable mutants. Each subculturing cycle was counted as one generation as the excised explants regenerated into new plantlets. Irradiated stevia in vitro plantlets exhibited significantly $(p<0.05)$ longer shoot length of $10.16 \pm 1.85 \mathrm{~cm}$, higher number of leaves $(16.07 \pm 5.19)$ and greater leaf size $(1.12 \pm 0.26 \mathrm{~cm}$ x $0.54 \pm 0.15 \mathrm{~cm})$ compared to non-irradiated in vitro plantlets. It can be said that the growth of 
stevia plantlets were significantly improved when exposed to gamma irradiation of $23 \mathrm{~Gy}\left(\mathrm{LD}_{50}\right)$. Similar observations were reported by Yadav (2016) where there was significant increase in leaf numbers of Canscora decurrens Dalz plants exposed to low irradiation doses than the control plants. Such "low dose-high growth" correlation was also observed in several plants such as Molluccella lavis (Minisi et al., 2013), Cucurma longa (Ilyas \& Naz,
2014), Hibiscus sabdariffa (Sherif \& Sarwat, 2005), and Dracaena serculosa (Sakr, 2005). A broad range of negative activities at plant physiological levels such as water exchange, leaf gas exchange, enzymatic and hormonal imbalance, and alteration in protein synthesis were triggered at higher doses of gamma rays (Hameed et al., 2008).

Table 2. Effect of different doses of acute gamma irradiation on growth of regenerated stevia variety AKH L1 shoots after one month.

\begin{tabular}{|c|c|c|c|c|}
\hline Dose (Gy) & $\begin{array}{c}\text { Survival rate } \\
(\% \pm S D)\end{array}$ & $\begin{array}{c}\text { Length of } \\
\text { regenerated } \\
\text { shoot } \\
\text { (mean } \pm S D)\end{array}$ & $\begin{array}{c}\text { No. of new } \\
\text { shoots formed } \\
\text { (mean } \pm \text { SD) }\end{array}$ & $\begin{array}{r}\text { No. of leaf } \\
(\text { mean } \pm S D)\end{array}$ \\
\hline 0 & $100 \pm 0.00^{\mathrm{a}}$ & $2.53 \pm 0.36^{\mathrm{a}}$ & $1.84 \pm 0.63^{\mathrm{a}}$ & $16.52 \pm 5.05^{\mathrm{a}}$ \\
\hline 10 & $93.33 \pm 8.33^{\mathrm{a}}$ & $2.44 \pm 0.67^{a}$ & $1.72 \pm 0.38^{a}$ & $15.77 \pm 5.66^{\mathrm{a}}$ \\
\hline 20 & $58.67 \pm 12.86^{\mathrm{b}}$ & $1.76 \pm 0.78^{\mathrm{ab}}$ & $0.73 \pm 0.37^{\mathrm{b}}$ & $13.35 \pm 4.86^{\mathrm{ab}}$ \\
\hline 30 & $37.33 \pm 16.65^{c}$ & $1.40 \pm 0.55^{\mathrm{bc}}$ & $0.31 \pm 0.19^{\mathrm{bc}}$ & $8.80 \pm 3.56^{\mathrm{abc}}$ \\
\hline 40 & $14.67 \pm 4.62^{\mathrm{d}}$ & $1.05 \pm 0.13^{\mathrm{bc}}$ & 0.00 & $6.89 \pm 1.92^{\mathrm{bc}}$ \\
\hline 50 & $9.33 \pm 8.33^{\mathrm{d}}$ & $0.47 \pm 0.28^{c}$ & 0.00 & $2.81 \pm 2.47^{c}$ \\
\hline
\end{tabular}

Data was taken from five replicates (with five explants per replicate) and the experiment was carried out three times. Superscripts within the means of each column (a-d) indicate significant difference among means ( $<<0.05$, using Duncan's Multiple Range Test). SD = standard deviation.
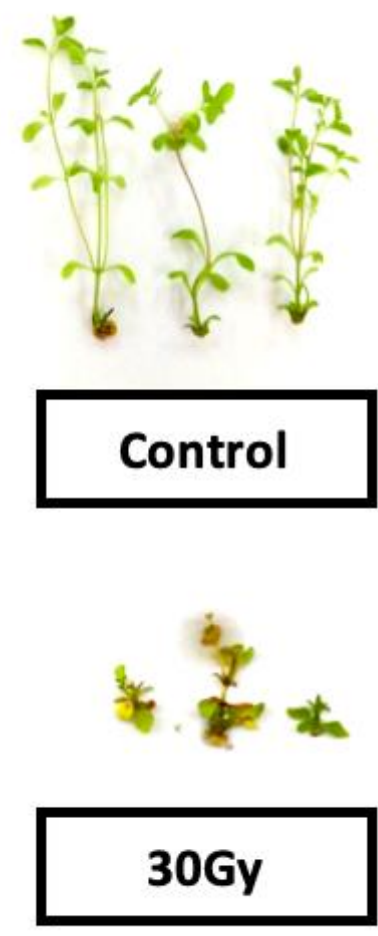
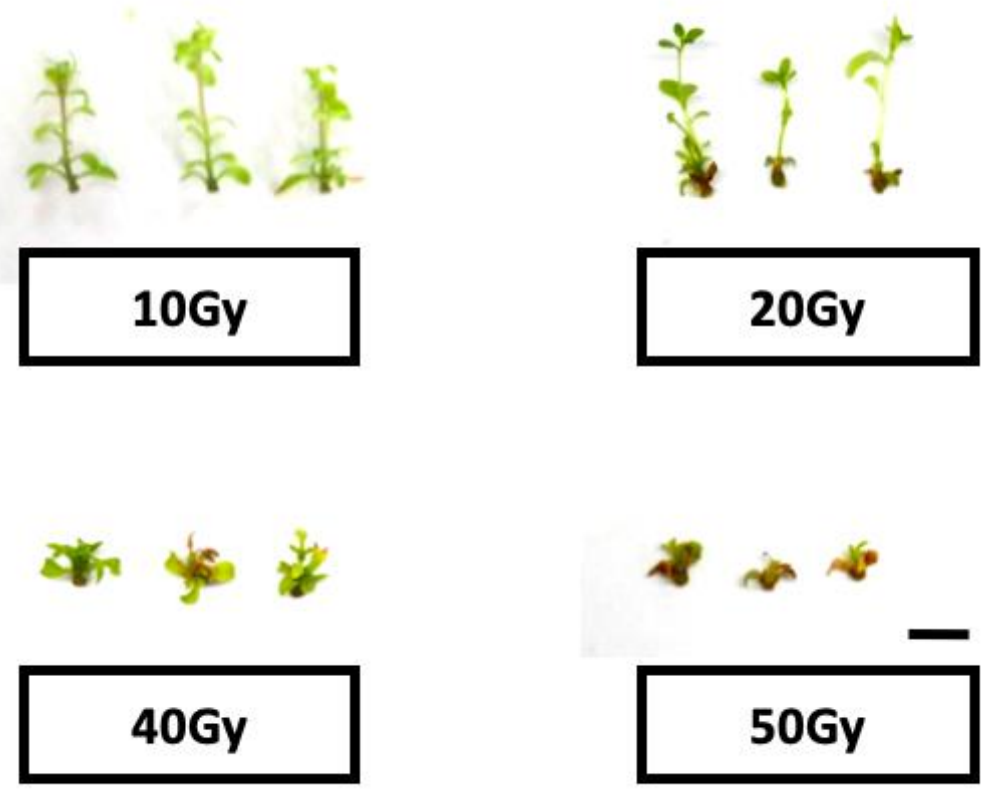

Figure 5. Effects of acute gamma irradiation on growth of regenerated stevia variety AKH L1 shoots after one month of culture on MS medium supplemented with $1 \mathrm{mg} / \mathrm{L}$ 6-benzylaminopurine $(\mathrm{BAP})$. Bar= $1 \mathrm{~cm}$. 
Table 3. Comparison of control and irradiated stevia variety AKH L1 plantlets at $\mathrm{LD}_{50}(23 \mathrm{~Gy})$ after four generations.

\begin{tabular}{ccc}
\hline Parameter & Control & Irradiated \\
\hline No. of explant survived (\%) & $95.83^{\mathrm{a}}$ & $87.18^{\mathrm{b}}$ \\
No. of shoot / explants & $6.20 \pm 2.39^{\mathrm{a}}$ & $2.60 \pm 0.90^{\mathrm{b}}$ \\
Length of shoot / explant (cm) & $8.61 \pm 3.40^{\mathrm{a}}$ & $10.16 \pm 1.85^{\mathrm{b}}$ \\
No. of leaf / explants & $13.33 \pm 5.42^{\mathrm{a}}$ & $16.07 \pm 5.19^{\mathrm{b}}$ \\
Average leaf size, & $0.81 \pm 0.22$ & $1.12 \pm 0.26$ \\
Length x Width (cm) & $\mathrm{x}$ & $\mathbf{x}$ \\
& $0.44 \pm 0.14^{\mathrm{a}}$ & $0.54 \pm 0.15^{\mathrm{b}}$
\end{tabular}

The data presented was mean $\pm S D$ of $n=300$, and the experiment was repeated twice. Superscripts within the means (a-b) indicate significant difference among means ( $\mathrm{p}<0.05$ using One-Sample T Test).

\section{Determination of steviol glycosides (SGs) using high performance liquid chromatography (HPLC) analysis. An} isocratic HPLC method was validated to determine the concentration of stevioside, rebaudioside $\mathrm{A}$ and rebaudioside $\mathrm{D}$ as described by Nishiyama et al. (1992). The retention times of the stevioside, rebaudioside $\mathrm{A}$ and rebaudioside $\mathrm{D}$ standards were recorded at 3.98 mins, 3.96 mins, and 3.56 mins, respectively (Table 4).

A standard curve was used to determine the concentration of each steviol glycoside in the irradiated and non-irradiated stevia leaf extracts. Based on Figure 6, the concentration of each steviol glycoside tested was higher (about three folds increment) in irradiated plantlets compared to the control leaf extract. From the HPLC results, a new stevia variety of AKH L1 was characterized with higher stevioside (387.04 ppm), rebaudioside A (670.18 ppm) and rebaudioside D (106.26 ppm).

Rebaudioside A and stevioside made up the majority proportion of the total steviol glycosides contents whereby the ratio of rebaudioside A to stevioside determined the sweetness quality of stevia (Yadav et al., 2011). Similarly, Khalil et al. (2014) reported that gamma irradiation at 15Gy produced slightly enhanced stevioside contents in their irradiated plants. Other reports, however, claimed that increasing gamma ray doses induced higher mutation rates while at the same time led to significant reduction in stevioside contents in the stevia plants (Predieri, 2010; Ali et al., 2015). Such conflicting findings probably could be due to different varieties of stevia used in the experiments, and the different environment and physical conditions where the experiments were conducted.

Table 4. Retention time of standard steviol glycosides: Stevioside, Rebaudioside A, and Rebaudioside D, all done under separation of acetonitrile/water as the elution solvent at flow rate of $0.8 \mathrm{~mL} / \mathrm{min}$, and the detection wavelength set at $210 \mathrm{~nm}$.

\begin{tabular}{cc}
\hline Steviol glycosides & Retention time (min) \\
\hline Stevioside & 3.98 \\
Rebaudioside A & 3.96 \\
Rebaudioside D & 3.56 \\
\hline
\end{tabular}

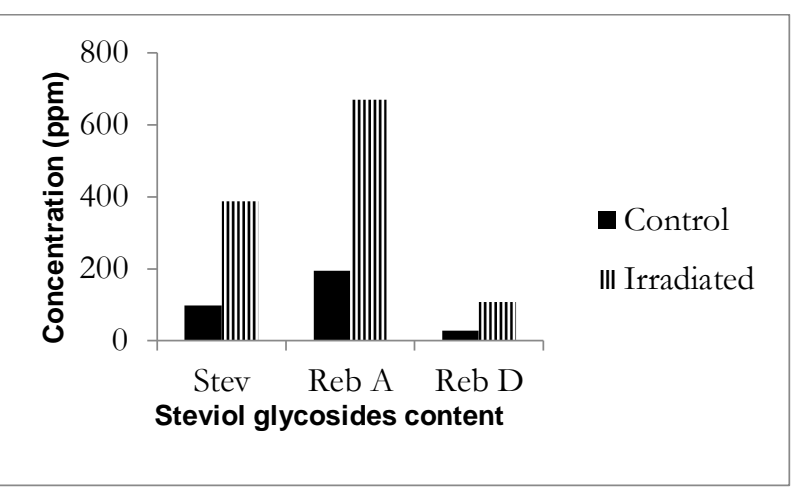

Figure 6. Steviol glycosides content in irradiated and non-irradiated (control) stevia leaf samples. Stev $=$ stevioside; Reb $\mathrm{A}=$ rebaudioside $\mathrm{A}$; and Reb D = rebaudioside $\mathrm{D}$. 


\section{CONCLUSION}

Acute gamma irradiation was found to be a clean and effective method to induce mutations in Stevia rebandiana varieties. All irradiated in vitro AKH L1 plantlets exhibited different survival rates, with the lowest at $9.33 \pm 8.33 \%$ subjected to $50 \mathrm{~Gy}$. The high irradiation dose produced plants exhibiting poor growth and development (necrotic leaves, reduced shoot length and number of leaves). Nevertheless, determination of the $\mathrm{LD}_{50}$ provided an effective dose at 23Gy whereby irradiated plantlets showed significant improvement in phenotypic characteristics and steviol glycosides contents, especially stevioside and rebaudioside A. The data obtained can be further applied to develop new stevia plants with other improved features using acute gamma irradiation.

\section{ACKNOWLEDGEMENTS}

Authors would like to thank management and staff of Malaysia Nuclear Agency for their technical assistance on irradiation. We acknowledge Universiti Putra Malaysia for funding this project under the Putra Grant No. GP-IPB/2016/9490300.

\section{REFERENCES}

Abou-Arab, A. E., Abou-Arab, A. A., \& Abu-Salem, M. F. 2010. Physico-chemical assessment of natural sweeteners steviosides produced from Stevia rebaudiana Bertoni plant. African Journal of Food Science 4: 269-281.

Ahmad, N., Fazal, H., Zamir, R., Khalil, S. A., \& Abbasi, B. H. 2011. Callogenesis and shoot organogenesis from flowers of Stevia rebaudiana (Bert.). Sugar Technology 13: 174-177.

Ali, A. A., Aboshosha, A. A., Kassem, M. K., EL-Dabaawy, E. I., \& EL-Banna, A. N. 2015. Salinity tolerance and stevioside improvement of in vitro selected stevia (Stevia rebaudiana) mutants. International Journal of Current Research in Bioscience and Plant Biology 2: 11-20.

Armizatul, S. A. H., Azhar, K., \& Nazrul, R. 2009. Influence of lengthening day on stevia vegetative growth. Transaction of the Malaysian Society of Plant Physiology 18: 17-18.

Carakostas, M. C., Curry, L. L., Boileau, A. C., \& Brusick, D. J. 2008. Overview: The history, technical function and safety of rebaudioside A, a naturally occurring steviol glycoside, for use in food and beverages. Food and Chemical Toxicology 46: $1-10$.

Ceballos, H., Sánchez, T., Denyer, K., Tofiño, A. P., Rosero, E. A., Dufour, D., Smith, A., Morante, N., Pérez, J. C., \& Fahy, B.
2008. Induction and identification of a small-granule, highamylose mutant in cassava (Manibot esculenta Crantz). Journal of Agricultural and Food Chemistry 56: 7215-7222.

Chen, X., Liu, X., Wu, D., \& Shu, Q. Y. 2006. Recent progress of rice mutation breeding and germplasm enhancement in China. Plant Mutation Reports 1: 4-6.

Dubois, G. E. (2000). Sweeteners: non-nutritive. In: Francis FJ (ed.) Encyclopedia of Food Science and Technology. John Wiley and Sons, Inc., New York, NY. pp 2245-2265.

El-Motaleb, M. A., El-Hady, M. A. S., El-Kholy, M. A., \& Badr, A. 2013. In vitro propagation of Stevia rebaudiana Bertoni in Egypt. Journal of Applied Science Research 9: 4597-4605.

Filipecki, M., \& Malepszy, S. 2006. Unintended consequences of plant transformation: a molecular insight. Journal of Applied Genetics 47: 277-286.

Hameed, A., Shah, T. M., Atta, B. M., Haq, M. A., \& Sayed, A. 2008. Gamma irradiation effects on seed germination and growth, protein content, peroxidase and protease activity, lipid peroxidation in desi and kabuli chickpea. Pakistan Journal of Botany 40: 1033-1041.

Hase, Y., Tanaka, A., Baba, T., \& Watanabe, H. 2000. FRL1 is required for petal and sepal development in Arabidopsis. The Plant Journal 24: 21-32.

Hase, Y., Tanaka, A., Baba, T., \& Watanabe, H. 2000. FRL1 is required for petal and sepal development in Arabidopsis. The Plant Journal 24: 21-32.

Ilyas, S., \& Naz, S. 2014. Effect of irradiation on morphology characteristics and isolation of cucurminoids and oleeoresoids of Cucurma longa L. The Journal of Animal \& Plant Sciences 24: 1396-1404.

Jain, S. M. 2010. Mutagenesis in crop improvement under the climate change. Romanian Biotechnological Letters 15: 88-106.

Jamie, H. 2002. Induced Mutations: Increasing Agricultural Quality and Yield of Tomato. Athena High Schools. Science Research Program, Greece, pp 132-145.

Kangarasu, S., Ganeshram, S., \& Joel, A. J. 2014. Determination of lethal dose for gamma rays and ethyl methane sulphonate induced mutagenesis in cassava (Manibot esculenta Crantz.). International Journal of Scientific Research 3: 3-6.

Khalil, S. A., Zamir, R., \& Ahmad, N. 2014. Effect of different propagation techniques and gamma irradiation on major steviol glycoside's content in Stevia rebaudiana. Journal of Animal and Plant Science 24: 1743-1751.

Khalil, S. A., Zamir, R., \& Ahmad, N. 2014. Effect of different propagation techniques and gamma irradiation on major steviol glycoside's content in Stevia rebaudiana. Journal of Animal and Plant Science 24: 1743-1751.

Lester, T. 1999.Stevia rebaudiana sweet leaf. The Australian New Crops Newsletter 11: 1

Mathur, S., \& Shekhawat, G.S. 2012. Establishment and characterization of Stevia rebaudiana (Bertoni) cell suspension culture: An in vitro approach for production of steviosides. Acta Physiologiae Plantarum 35: 931-939.

Minisi, F. A., El-mahrouk, M. E., El-Din, M. Rida., \& Nasr, F. N. 2013. Effects of gamma radiation on germination, growth characteristics and morphological variations of Moluccella laevis L. American-Eurasian Journal of Agricultural and Environment Science 13: 696-704.

Miyagawa, H., Fujioka, N., Kohda, H., Yamasaki, K., Taniguchi, K., \& Tanaka, R. 1986. Studies on the tissue culture of Stevia rebaudiana and its components (IInd) Induction of shoot primordia. Planta Medica 45: 321-322.

Mubarak, M. H., Belal, A. H., EL-Geddawy, I. H., EmanI. ELSarag \& Nasr, M. I. 2008. Micropropagation of Stevia rebaudiana in vitro. Meeting the challenges of sugar crops and integrated industries in developing countries. Journal of Applied Science Research 9: 293-298. 
Muradoglu, F., Balta, F., \& Battal, P. 2010. Endogenous hormone levels in bearing and non-bearing shoots of walnut (Juglans regia L.) and their mutual relationships. Acta Physiologiae Plantarum 32: 53.

Murashige, T. \& Skoog, F. 1962. A revised medium for rapid growth and bioassays with tobacco tissue culture. Physiology Plant 15: 473-497.

Nakasha, J. J., Sinniah, U. R., Kemat, N., \& Mallappa, K. S. 2016. Induction, subculture cycle, and regeneration of callus in safed musli (Chlorophytum borivilianum) using different types of phytohormones. Pharmacognosy Magazine 12: 460.

Nishiyama, P., Alvarez, M., \& Vieira, L. G. 1992. Quantitative analysis of stevioside in the leaves of Stevia rebaudiana by near infrared reflectance spectroscopy. Journal of the Science of Food and Agriculture 59: 277-281.

Nurhidayah, S., Norazlina, N., \& Rusli, I. 2014. Effect of Acute Gamma Irradiation on in vitro Growth of Stevia rebaudiana Bertoni. Innovative Plant Productivity and Quality 22: 214-217.

Oladosu, Y., Rafii, M. Y., Abdullah, N., Hussin, G., Ramli, A., Rahim, H. A., \& Usman, M. 2016. Principle and application of plant mutagenesis in crop improvement: a review. Biotechnology and Biotechnological Equipment 30: 1-16.

Patil, V., Ashwini, K. S., Reddy, P. C., Purushotham, M. G., Prasad, T. G. \& Udayakumar, M. 1996. In vitro multiplication of Stevia rebaudiana. Current Science 70: 960.

Petolino, J. F., Roberts, J. L., Jayakumar, P. 2003. Plant cell culture: a critical tool for agricultural biotechnology. In: Vinci $V A$, Parekh SR (eds.) Handbook of industrial cell culture: mammalian, microbial and plant cells. New Jersey : Humana Press, p243258.

Predieri, S. 2001. Mutation induction and tissue culture in improving fruits. Plant Cell, Tissue and Organ Culture 64: 185210.

Preussa, S. B., \& Britta, A. B. 2003.A DNA-damage-induced cell cycle checkpoint in Arabidopsis. Genetics 164: 323-334.

Rajarajan, D., Saraswathi, R., \& Sassikumar, D. 2016. Determination of lethal dose and effect of gamma ray on germination percentage and seedling parameters in ADT (R) 47 Rice. International Journal of Advanced Biological Research 6: 328-332.

Ramanand, M. L. 2004. An efficient protocol for in vitro micropropagation of sugarcane. Sugar Tech 6: 85-87.

Reis, R. V., Borges, A. P. P. L., Chierrito, T. P. C., Souto, E. R., Souza, L. M., Lacomini, M., Oliveira, A. J. B., \& GoncAlves, R. A. C. 2011. Establishment of adventitious root culture of Stevia rebaudiana Bertoni in a roller bottle system. Plant Cell, Tissue and Organ Culture 28: 151-157.

Sakr, K. 2005. Effect of high temperature or fire in heavy weight concrete properties. Cement and Concrete Research 35: 590-596.

Sherif, M. H., \& Sarwat, M. I. 2005. Physiological and chemical variations in producing rosette plant (Hibiscus sabdariffa L.) by using some organic farmyard manure. World Journal of Agricultural Sciences 3: 609-616.

Shikazono, N., Yokota, Y., Kitamura, S., Suzuki, C., Watanabe, H., Tano, S., \& Tanaka, A. 2003. Mutation rate and novel the Mutants of Arabidopsis thaliana induced by carbon ions. Genetics 163: 1449-1455.

Tadhani, M. B., Jadeja, R. P., \& Rena, S. 2006. Micropropagation of Stevia rebaudiana Bertoni using multiple shoot culture. Journal of Cell and Tissue Research, 6, 545-548.

Tah, P. R. 2006. Studies on gamma ray induced mutation in mungbean (Vigna radiate (L.) Wilezek). Asian Journal of Plant Sciences 5: 61-70.

Tanaka, A., Sakamoto, A., Ishigaki, Y., Nikaido, O., Sun, G., Hase, Y., Shikazono, N., Tano, S., \& Watanabe, H. 2002. An ultraviolet-B resistant mutant with enhanced DNA repair in Arabidopsis Plant Physiology 129: 64-71.
Thiyagarajan, M., \& Venkatachalam, P. 2012. Large scale in vitro propagation of Stevia rebaudiana (bert) for commercial application: Pharmaceutically important and antidiabetic medicinal herb. Industrial Crops and Products 37: 111-117.

Tomlekova, N. B. 2010. Induced mutagenesis for crop improvement in Bulgaria. Plant Mutation Reports 2: 4-27.

Uddin, M. S., Chowdhury, M. S. H., Khan, M. M. M. H., Uddin, M. B., Ahmed, R., \& Baten, M. A. 2006. In vitro propagation of Stevia rebaudiana Bert in Bangladesh. African Journal of Biotechnology 5: 1238-1240.

Wi, S. G., Chung, B. Y., Kim, J. S., Kim, J. H., Baek, M. H., Lee, J. W., \& Kim, Y. S. 2007. Effects of gamma irradiation on morphological changes and biological responses in plants. Micron 38: 553-564.

Yadav, A. K., Singh, S., Dhyani, D., \& Ahuja, P. S. 2011. A review on the improvement of stevia [Stevia rebaudiana (Bertoni)]. Canadian Journal of Plant Science 91: 1-27.

Yadav, V. 2016. Effect of gamma radiation on various growth parameters and biomass of Canscora decurrens Dalz. International Journal of Herbal Medicine 4: 109-115. 